\title{
Construction of Multimodal Transport Information Platform
}

\author{
Ya Wang ${ }^{1}, Y u$ Cheng $^{1}$, and Zhi Zhao ${ }^{1, *}$ \\ ${ }^{1}$ Shandong Jiaotong University, Ji’nan, Shandong 250300, China
}

\begin{abstract}
With the rapid development of economy, the volume of transportation in China is increasing, the opening process of the market is accelerating, the scale of enterprises is expanding, the service quality is being improved, and the container multimodal transport is developing continuously.The hardware infrastructure of container multimodal transport is improved obviously, but the network platform construction of multimodal transport is still insufficient.Taking Shandong region of China as an example, the present situation of container multimodal transport in Shandong area can no longer meet the requirement of rapid development of container, and the construction of network platform needs to be solved urgently. Therefore, this paper will briefly describe the conception of construction of multimodal transport network platform in Shandong area.In order to achieve the rapid development of multimodal transport.
\end{abstract}

\section{Introduction}

The construction of multimodal transport information platform can effectively avoid the traditional mode of strip management.The innovation of the operation mode of container multimodal transport management can completely change the split state of container multimodal transport.Based on the complete public information service system, a safe and reliable multimodal transport information service network platform is constructed to improve the barriers of information transmission among various departments.In this way, all kinds of transportation modes and transportation resources can be effectively coordinated.

\section{Analysis on the Necessity of the Development of Multimodal Transport Information Platform in Shandong Province}

\subsection{Status quo and Policy Analysis of Multi- modal Transport Information platform Construction in Shandong Province}

In developed countries such as Europe and America, multimodal transport, especially container seaborne transport, has reached a high level. Developed countries such as the Netherlands, Germany and the United States attach particular importance to the application of information technology in container transportation, especially EDI technology.These developed countries have already established the EDI information network system, realized the high efficiency transmission and the sharing multimodal transport information, has ensured each kind of transportation mode close connection, has brought the advanced container transportation.

In China, various departments attach great importance to the informatization construction in their respective fields in multimodal transport, and also have a relatively high degree of informatization. However, because the information coordination platforms among the systems are not unified, each department system operates independently.There is a big gap between China and the developed countries.In the long run, ports, railway departments, shippers and agents have great constraints on information sharing and communication, which not only seriously affect the advantages of multimodal transport, but also do not meet the development momentum and needs of modern logistics.

In 2016, Shandong Provincial Transportation Department held a forum in Qingdao to promote the development of multimodal transport. The competent transportation departments and key freight, logistics, water and port enterprises in 14 cities of Shandong Province participated in the meeting.At the meeting, Inspector Gao Hongtao stressed that the development of multimodal transport and the construction of a new system of transportation and logistics integration and development are the "breakthrough points" for improving the efficiency and efficiency of the logistics industry.Aiming at the imperfect construction of multimodal transport information platform at present, the paper puts forward some important tasks such as strengthening information sharing of multimodal transport, innovating application of technology and equipment, unifying standard and so on.In addition, in recent years, Shandong Province under the leadership of the Department of Communications, Shandong Province port and shipping management to promote water-waterwater-water-water-water-water-water-water-water-water transport.At the provincial level, the related policies to

\footnotetext{
* Corresponding author: 1808708221@qq.com
} 
support multimodal transport should be put forward, and the information sharing platform of hot metal intermodal transport should be set up in a unified way to further improve the construction of comprehensive transportation system.It can be seen that the construction of multimodal transport information platform in Shandong Province receives great attention from the Transportation Department.

\subsection{Meet the needs of China's national policy development}

Informatization is the trend of the development of the contemporary world and the main force to promote the economic and social change.China has formulated the 《National Informatization Development Strategy from 2006 to 2020$\rangle$, which focuses on transforming and improving the development of traditional industries by using information technology, and making full use of information technology to promote the transformation of industries with high energy consumption, high material consumption and high pollution.Promote supply chain management and customer relationship management.

\subsection{Meet the needs of the current development of sea-rail intermodal transport}

The advantages of sea-rail transport such as different customs declaration, high punctuality, less intermediate links, large transportation capacity, etc., it can effectively reduce the transfer time and cost in freight transportation.As a green and low-carbon transport mode, sea-rail transport is more and more popular.Since 2003, China's container throughput has ranked first in the world, accounting for more than $40 \%$ of the world's total. The port container transportation volume is huge, the highway carries about $84 \%$, the water and water transport accounts for $14 \%$, the sea rail transport is less than $1.5 \%$, and in the major ports of Europe and the United States, the proportion of sea rail combined transport accounts for $20 \%$ or $30 \%$.

\subsection{Meet the need to reduce the cost of multimodal logistics}

At present, more than $80 \%$ of freight transportation in China still depends on road transportation, but the network transport capacity between road, railway, water transport and aviation is very poor, which also leads to higher logistics costs. The proportion of logistics cost to China's GDP is about twice that of developed countries. The high logistics cost weakens the competitiveness of Chinese manufacturing industry and hinders the development of Chinese economy.The public information platform of container multimodal transport can link logistics enterprises, industrial manufacturing enterprises and other enterprises to form a seamless alliance to transform the situation of logistics enterprises with many, small and dispersed.By enhancing the matching degree of capacity resources and sources of goods, increasing the number of Intensification, scale and professional level of intermodal transport to improve the efficiency and efficiency of multimodal transport and reduce the total cost of social logistics.

\section{Multimodal transport information platform architecture in Shandong}

For the construction of multimodal transport information platform in Shandong area and the optimization of the whole transportation process, its core is the maximum integrated utilization of information. The following are mainly from the perspective of the transport chain, in order to obtain accurate information for the purpose of integrating the information of all participants included in the transport chain.

\subsection{Center Platform Objectives and Functions}

Taking the core node of the container multimodal transport center in Weifang Port as an example, a high efficiency and low cost operation platform is established on its transportation chain.

Objective: to build an information management system that connects all participants in the transport chain from Weifang to all major hinterlands. The information platform is composed of an independent information management system, and accompanied by a certain degree of comprehensiveness and complexity. In the process of practical operation, these information management not only includes the advantages of modularization and networking of common information systems, but also has the advantages of integration, dynamic and real-time. In the process of constructing multimodal transport information platform, using the current advanced computer technology and cloud computing, a cross-system, multi-source heterogeneous, real-time integrated multimodal transport information system is established. Information platform. In this way, the inter-departmental information transmission can be realized, the coordination of various transport departments and the automation level of document flow can be improved, and then the interactive operation can be realized, and the efficiency and quality of multimodal transport can be greatly improved. Therefore, the multimodal transport information platform should meet the following conditions in practical use: the information management system for multimodal transport in the port transport area should contain the basic information of all transport participants, the basic information of the port area, Receive information, etc. Install docking ports in all information management systems, so that each system can share and exchange information data, so that data information can play the most important role. Great use value. Cloud computing technology can be used to ensure the real-time sharing of information, to strengthen the basic functions of multimodal transport information management system, to realize the shipper or consignee of the entire transportation of goods query. In a word, the purpose of multimodal transport information platform is to enhance the quality of information service and 
efficiency of intermodal transport system by information integration and sharing.

(2) Functions: basic information sharing includes highway network information, inland river and channel information, port comprehensive information, railway network information, railway container transportation information, shipping company information, transportation chain related geographic information, traffic management information,Information on all participants involved in the transport chain. Transport information sharing includes information about means of transport (state of transport, location, etc.), information of goods (state of goods, location of goods in transit, etc.), transportation schedule (difference from actual to outgoing time).The information sharing of supply and demand includes the demand and supply information of various transportation vehicles, warehouse demand information and cost calculation.

\subsection{Business logic structure construction}

The logical structure is based on user service, which aims to provide information transmission between different functions to meet the needs of users. The logical structure of the central information platform is shown in figure 1 .

\subsection{Information platform physical structure}

Transportation chain Management system (TCMS) is the main external information processing system of the information platform of the central station, which plays a key role in the fast and stable operation of the whole transportation chain.As the central database and central data processing system of the Ministry of Railways, the Transportation Information Management system is responsible for grasping the dynamic information of railway transportation in real time, reflecting the dynamic data report of the transportation in real time, and providing service for the relevant business departments and customers. Therefore, the establishment of multimodal transport information system in Shandong can try TCMS system. Taking Weifang Port Intermodal Transport Center as an example, the physical structure of the information platform can be set up as shown in the figure 2 .

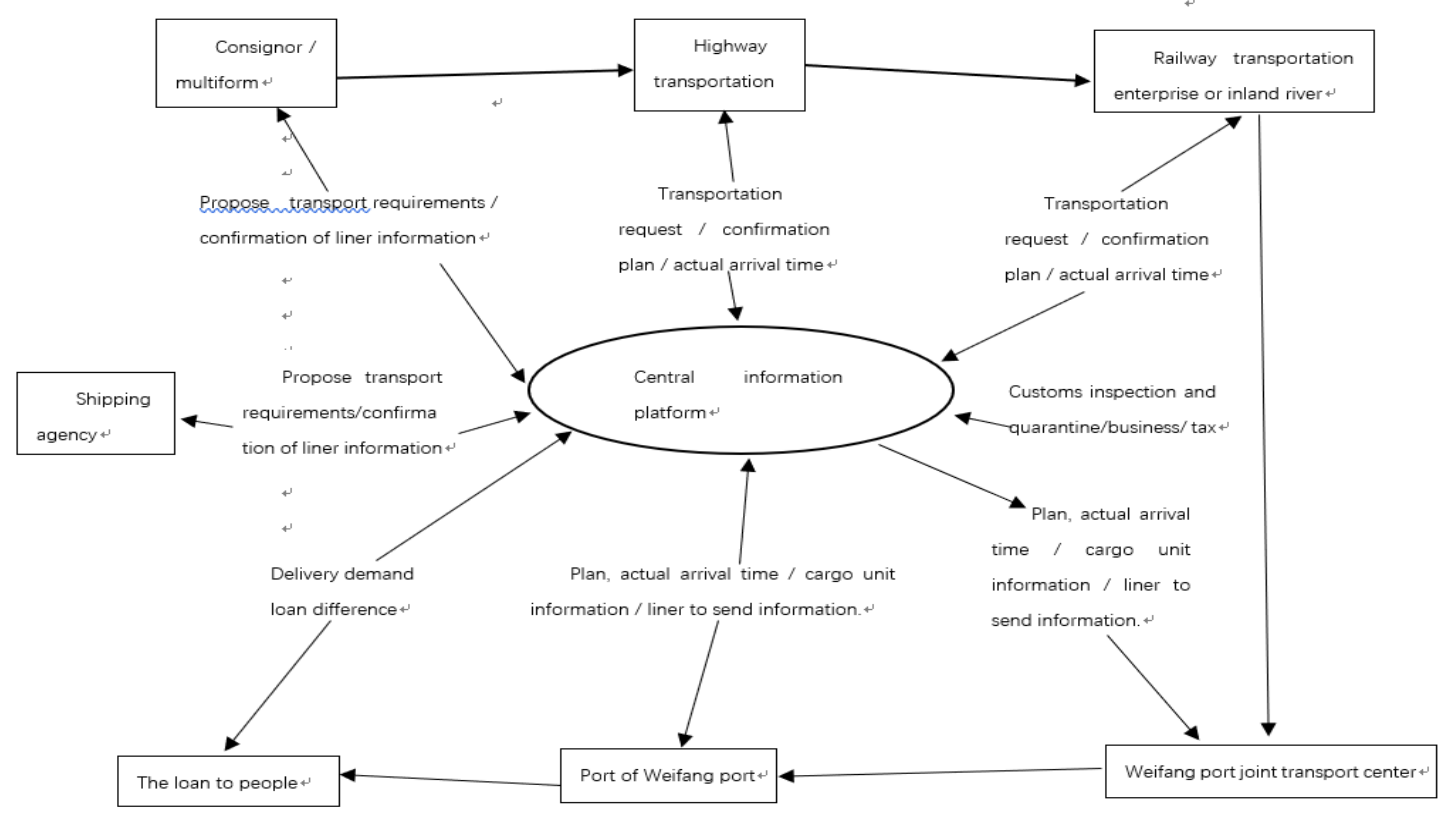

Fig. 1. Logical structure diagram of central information platform 


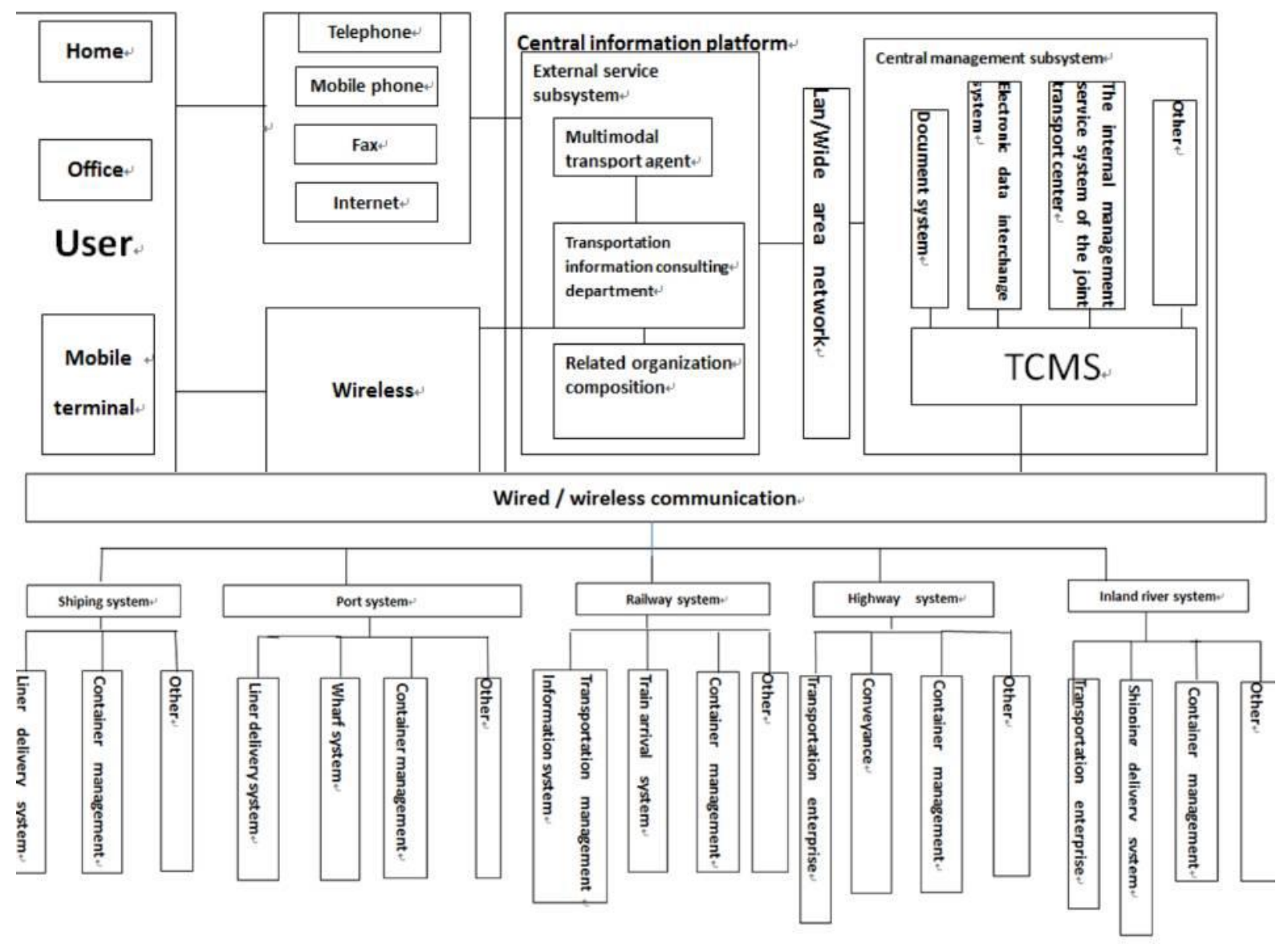

Fig. 2. Physical structure of information platform

\section{Conclusion}

China multimodal transport has entered a rapid development stage, but the level of information is not high, the departments are relatively independent.This paper takes the core node of the container multimodal transport center in Weifang Port, Shandong Province as an example to illustrate how to construct the business structure and overall framework of the information platform.Through the establishment of multimodal transport information platform, various modes of transportation are effectively connected based on information technology, so as to realize the continuous, safe and efficient multimodal transport of goods.

\section{References}

1. Jia Jingjing. On the construction of multimodal transport information platform in port[J]. Journal of
Chongqing Jiaotong University: Social Sciences, 2010.10 .

2. Fang Tiange, Zhang Xiuyang. On the construction of multimodal transport information platform[J]. Xi'an: School of Economics and Management, Chang'an University, 2015.

3. Zhang Heng, Zhang Jiguo. Strategy of Information Platform for Port Logistics Center [J]. Logistics Technology, 2003(8).

4. Jia Limin, Li Ping, Qin Yong. Research on the Framework of China's Railway Intelligent Transportation System[J]. Chinese Railways, 2003(11).

5. Zhang Hao, Liu Zhiqi. Research on the information platform framework of container multimodal transport center [J]. Shanghai: School of Transportation Engineering, Tongji University, 2016.2 . 